\title{
Mapping students' interest in a new domain: Connecting prior knowledge, interest, and self-efficacy with interesting tasks and a lasting desire to reengage.
}

Luke K. Fryer, Faculty of Education (CETL), The University of Hong Kong, Hong Kong Alex Shum, Faculty of Science, The University of Hong Kong, Hong Kong

Ada Lee, CETL, The University of Hong Kong, Hong Kong

Peter Lau, CETL, The University Hong Kong, Hong Kong

\section{Author Note}

Luke K. Fryer Đhttps://orcid.org/0000-0001-6250-5950

Alex Shum: (iD https://orcid.org/0000-0001-6223-787X

We have no known conflicts of interest to disclose.

Correspondence concerning this article should be addressed to Luke K Fryer, The University of Hong Kong, Pokfulam Rd. Centennial Campus, Hong Kong.

Email: lukefryer@yahoo.com

Funding: The research presented herein was partially funded by a Hong Kong General Research Fund grant (\#17615218) and a Hong Kong University Teaching Development Grant \# 707 to the first and second authors.

\section{Acknowledgements}

The authors would like to express their appreciation to Mary Ainley for her review of an earlier draft of this manuscript and her kind support for the overall research programme.

\section{ONLINE PRE-PRINT VERSION}

The final version will be available for download here:

https ://doi.org/10.1016/j.learninstruc.2021.101493

\section{Please reference as:}

Fryer, L. K., Shum, A., Lee, A., \& Lau, P. (2021). Mapping students' interest in a new domain: Connecting prior knowledge, interest and self-efficacy with interesting tasks and a lasting desire to reengage. Learning and Instruction. https ://doi.org/10.1016/j.learninstruc.2021.101493 


\begin{abstract}
How students experience educational environments and the interconnections between their readiness, task experiences and their long-term desire to reengage with course content are critical questions for educators. Research postgraduate students $(n=310)$ at a researchintensive university in Hong Kong, engaging in a 24-hour introductory teaching course, participated in this study. Learner readiness for the course was assessed as prior Domain interest, self-efficacy, and knowledge. Subsequently, students completed four formative assessments, reported their on-task interest in seven strategically chosen tasks and end-ofcourse Course and Domain interest. Longitudinal-SEM tested interconnections between readiness components, Task, Course and Domain interest. Initial self-efficacy beliefs for teaching predicted early Task interest, while Domain interest was a predictor of Task interest in explicitly practical task experiences. Strong interconnections between Task interest across the study were evident. Individual written and social (discussion) tasks presented strong contributions to future Course/Domain interest. Implications for theory and practice are discussed.
\end{abstract}

\title{
Keywords:
}

Interest, Longitudinal Latent SEM, Micro-analytic 


\section{Introduction}

Decades of research have and continue to refine our understanding of interest as a complex psychological process integral to learning, which in the current study is defined broadly as a desire to reengage with an object ${ }^{1}$ (Renninger \& Hidi, 2016). Applying this growing understanding to the structures of formal education students and teachers work within has the potential to enhance student learning processes (Thoman et al., 2017) and outcomes (Jansen et al., 2016). Furthermore, it also has the potential to address persistent educational issues (e.g., female student STEM engagement; Hoffman, 2002). The approach in the current study is to consider the development of interest in a specific learning domain as the outcome of students' readiness to engage in a relevant course in the form of prior knowledge, Domain interest and self-efficacy, in combination with on-task interest experiences and developing Course interest.

The Four Phase Model of interest (i.e., Stimulated, Maintained, Emerging and Welldeveloped Individual, see section 2.2; Hidi \& Renninger, 2006; Renninger \& Hidi, 2011) is a useful guide to understanding how environments can affect the development of an individual's interest across a series of engagements with an object. Any application of the Four Phase Model to courses and classes, however, must strike a balance between the accumulated theory the model organises and practicality for stakeholders. This application to course/classroom practice needs to provide direction for educators, while still feeding into the ongoing theoretical discussions surrounding interest as a learning process and outcome. A refocusing of the phases of development as they apply to classroom experiences can achieve this aim. This begins by building from the readiness students bring with them to every new learning environment (Renninger \& Hidi, 2020). Central to this readiness are the prior Domain interest (i.e., a desire to reengage with the domain; Renninger \& Hidi, 2016), prior knowledge, and self-efficacy (i.e., in the current study, an individual's beliefs that s/he has the ability to successfully teach) for the course of study that students come with. From this base, the cumulative student experience, assessed as a series of interconnected interest in tasks (in class, online and independently), can be framed as a pattern, potentially building their interest in the specific course and through/to students' broader interest in the domain of study. 
Several longitudinal studies on interest across semesters and a year of school have been undertaken (e.g., Fryer \& Ainley, 2019; Grigg et al., 2018; Marsh et al., 2005; Xu, 2018). However, because the focus of these studies has been on individual interest, they have done little to illuminate the contribution of specific classroom experiences for the development of students' interest in a specific domain of study. A refocus of the phases of interest (Four Phase Model; Hidi \& Renninger, 2006) on students' course specific experiences can ameliorate this weakness by offering a detailed map of how week-to-week learning experiences can feed into students' interest for the objects of formalised learning.

The current study was designed to begin to address this gap and lay the groundwork for curriculum-level interventions in students' interest development. The current study pursued a micro-analytic research design across a mandatory course in how to teach for research postgraduate students (Ph.D. and MPhil students from 10 faculties). This study attempted to draw a detailed map, establishing pathways from students' readiness in the form of prior Domain interest, prior Domain knowledge and self-efficacy, to students' interest in specific task experiences, and on to students' Course and Domain interest at the end of the course. For the current study, readiness refers to the constituent components of an individual's ability "to focus, comprehend, and problem-solve" tasks and activities in a given context (Renninger \& Hidi, 2020, p. 15).

\section{Background}

\subsection{A growing focus on student interest as a learning resource and outcome}

The importance of interest as a fundamental psychological resource for engaging with the wider world (James, 1983/1892) and navigating formal education (Dewey, 1913) has long been proclaimed. Parallel to the continued refinement of our theories of interest and its covariates (e.g., Ainley, 2017; Peterson \& Hidi, 2019; Renninger \& Su, 2019), there is a growing call for interest to be treated not only as an essential resource for learning, but also as a central outcome (Harackiewicz et al., 2016; Hidi, 1990; Renninger \& Hidi, 2020).

Many of the studies that have worked to address and amplify this call, have done so by developing and testing targeted interest interventions from a single theoretical perspective: For example, mindsets (Burnette et al., 2020) or utility-value (Hulleman et al., 2010; Shin et al., 2019). Researchers have also tested the potential support of educational technology: For example, virtual environments (Chen et al., 2016), AI learning partners (Fryer et al., 2017) and personalised tutors (Walkington \& Bernacki, 2019). Other researchers have examined the 
impact of specific types of experiential learning: For example, museum visits (Schwan et al., 2014) and the pursuit of hobbies (Azevedo, 2013). Less common, but perhaps more sustainable, contributions to supporting interest as a key outcome of learning, are curriculumlevel studies seeking to explain how classroom/course experiences build interest steadily over time. Xu et al. (2012) is an important qualitative example of this kind of research. By observing and interviewing teachers, $\mathrm{Xu}$ et al. revealed critical and culturally relevant factors for instruction that support interest in science during elementary school. Furthermore, they reported how specific kinds of classroom interactions can play a role within the development of student interest. Quantitative research can also make a serious contribution to our understanding of how classroom learning experiences might support the development of students' interest. However, it must be seamlessly integrated into classroom experiences (e.g., for an on-task quantitative approach see Moeller et al., 2020). Such research needs to enable the advanced modelling necessary to establish the relative impact of students' readiness (e.g., prior Domain interest, knowledge and self-efficacy) on and through learning experiences, toward the Domain interest students can take with them to their next semester, year and the world beyond. Students' readiness (Renninger \& Hidi, 2020) is critical for such a mapping because the interest and knowledge students bring with them to a task can play a substantial role in task interest experiences.

The current study builds on a well-established model of interest (Four Phase Model: Hidi \& Renninger, 2006). It refocuses the phases and provides a means of clarifying the connections between students' initial readiness for, and micro-analytic interest in experiences in classrooms and across courses of study. This refocus supports curriculum-level research and educational reforms targeting the development of student Domain interest in subjects. This approach draws on and tests our burgeoning understanding of the contributions of selfefficacy (Hidi et al., 2007) and prior knowledge (Fryer \& Ainley, 2019; Rotgans \& Schmidt, 2017) for future interest. Finally, this study focuses on the connections between students' interest in specific classroom tasks, their current course and the broader domain under study (Fryer et al., 2016, 2017, 2019; Knogler et al., 2015; Nuutila et al., 2018, 2020).

\subsection{Interest Development: In theory and in formal education}

Research seeking to clarify the nature of interest, its development and contribution to learning has rapidly expanded in the past three decades. From a field with a significant emphasis on reading (e.g., Hidi \& Anderson, 1992; Schiefele, 1992, 1996), to a field which is increasingly central to STEM education (Hazari et al., 2017; Renninger et al., 2019) and 
learning in the workplace (Renninger \& Hidi, 2019), its progress is clear. This is exemplified by the developmental model that dominates most of the education-centred interest research: The Four Phase Model (Hidi \& Renninger, 2006; Renninger \& Hidi, 2011). Built on an initial dichotomy of situational and individual interest (Krapp et al., 1992), the Four Phase Model describes developmental stages while spelling out key environmental contributions. Interest development in the Four Phase Model begins with triggered situational interest: affective experience arising from and reliant on the environment. With continued engagement, maintained situational interest is the next potential phase: a multi-dimensional construct primarily affective but with increasing prominence of knowledge components and personal connections to the object. This type of interest is still reliant on the environment to be sustained. Bridging these situational interest phases to a more sustainable source of motivation, emerging individual interest is the next potential phase: a multi-dimensional construct which includes affective elements, with increasingly substantial knowledge and value components. Given sufficient reengagement this can lead to further knowledge of the object and a strong personal connection, interest can finally mature into a well-developed individual interest. This final phase of interest development has the potential to act as a motivational resource for further learning, driving reengagement with its object, supporting sustained knowledge and interest growth.

The Four Phase Model (Hidi \& Renninger, 2006; Renninger \& Hidi, 2011) provides a powerful source of hypotheses about the nature and development of interest, and its role within learning. In the context of a specific course of study, whether in a semester of a school subject or a course during tertiary education, there are benefits to focusing this model on objects specific to these learning environments. Within the context of a university course of study and when the focus of attention is the outcome of ongoing interest in the domain, the domain can be framed as the interest object, which, because it refers to a domain, necessarily encompasses more specific and localised objects. Hence, on the way to the development of an individual's Domain interest, for example, teaching, the student will encounter the specific localised levels of Task interest and the more general level of course interest within that broader domain. From the perspective of a student who is new to the domain, then the specific task is the interest object. This structure takes into account all four phases in the development toward a well-developed individual interest in the specific domain of study.

Within this organisation for interest development across a university course, three specific objects can provide a basis for researching interest development across a university course. First is the learning tasks students engage with across a course. Task interest is 
consistent with situational interest, with a specific task as its object (e.g., a discussion, completing a problem set, a quiz, a written assignment, a short lecture on a topic). This is consistent with Krapp's (2002) reference to interest at the level of current process. Knogler et al. (2015) demonstrated that measuring interest at the task level, taps both stimulated (constrained to that experience) and maintained (carried from task-to-task) interest. The second object is the course itself: that is, Course interest. Consistent with Hoffmann's (e.g., 2002) research in schools, interest in a course, or in her case a specific school subject, taught to a specific group of students, following a curriculum, with a specific teacher and for a set period of time. Course interest is a combination of students' interest in the environment wherein the learning takes place and the actual content under study. The third object is the broader Domain interest, separated from the course, as it is not confined to a group of students learning together, a specific curriculum, a teacher, or set period of time, for example Biology, Math, Earth Science, Sociology. This measurement of Domain interest is consistent with individual interest, with no clear distinction between emerging and well-developed phases. Focusing the Four Phase model in this manner makes it realistic to measure and model the interconnections between the practical components of interest development across a single university course.

An initial study, using this structure to understand how student's interest in learning a new language, modelled aspects of students' readiness (prior Domain interest, self-efficacy and self-concept) and their interest in three similar tasks across a 15-week course, followed by their Course interest and then the following week their post Domain interest (Fryer et al., 2016). Latent variable longitudinal modelling suggested strong pathways from readiness, measured as prior Domain interest and self-efficacy, through interest in a series of tasks, to Course interest, which subsequently predicted post Domain interest (Fryer et al., 2016). The lack of direct connection (prior Domain to Course interest), is hypothesised to be due partially to mediation through interest in course tasks, and partially due to the unique nature of Course interest (i.e., pairing of environmental and content constituent components).

Subsequent use of these levels of interest specificity (Task-Course-Domain), has been helpful in discerning task engagement that does and does not contribute to students' longerterm interest. An example in which differences in task engagement can be observed are simulation tasks done alone versus similar tasks with a social component. In recent studies, only interest in the task with a social component significantly predicted future interest in the course (Fryer et al., 2017, 2019; Fryer \& Bovee, 2020). Recent research with these levels of interest has also pointed to how perceptions of instruction impact Course interest, relative to 
students' prior Domain interest. For example, autonomy-supportive and well-structured instructional experiences were found to significantly predict Course interest whereas Prior Domain interest did not (Fryer \& Bovee, 2020). These studies established the utility of modelling interest at these levels of specificity. They point to the critical role of students' readiness, in terms of prior Domain interest and prior knowledge for the levels of Task interest students experience. Past studies (Fryer et al., 2017, 2019; Rotgans \& Schmidt, 2018) have demonstrated how the nature of a task interacts with prior Domain interest. Research connecting Task interest to future Course interest has suggested substantial differential impact of different task experiences on future Course and Domain interest. For example, teacher's perceptions (Fryer et al., 2017) and commonly held assumptions about active learning (Cavanagh, 2011) regarding behavioural engagement, indicated by teachers' observations of "active learning" during a task, in many cases does not correspond to students later developing Course interest. Conversely, tasks which teachers might see as less "active" can sometimes strongly predict future Course interest (Fryer et al., 2019).

When considering how task experiences might support Course and Domain interest, we need to consider the social component of classroom tasks. Social task components might play a role in connecting both students' readiness to Task interest, and Task interest with longer-term Domain interest. Pilot research for the present study suggested that sociallyorientated tasks were significantly related to higher future Course interest. These preliminary findings are consistent with the growing body of research pointing to the particular importance of the social valence of task experience for interest development (Bergin, 2016). For example, past research has highlighted the potential benefits of tasks which include an element of public performance (Bergin et al., 2013). Research also suggested that opportunities to be influenced by the interest of others' in a specific task or domain might be particularly relevant (Bergin, 1999).

The current study built on these findings by integrating a) readiness, represented by prior Domain interest, knowledge and self-efficacy, b) a detailed micro-analytic study examining Task interest across a series of course tasks, c) a series of formative assessments, representing ongoing knowledge acquisition, and d) their combined contribution to longerterm Course and Domain interest.

\subsection{Readiness: The role of prior knowledge and self-efficacy}

Prior knowledge is a critical element of students' readiness, impacting students' task interest, engagement and achievement (Dochy et al., 1999). Prior knowledge, and the 
continued acquisition of further knowledge, is theorised to work through and alongside students' self-efficacy beliefs (Bandura, 1993). According to Alexander (2003), students' knowledge grows as students' Domain interest and associated cognitive strategies deepen. Meta-analytic findings suggest that interest is consistently related to achievement ( $r=.30$; Schiefele et al., 1993). Rotgans and Schmidt's (2018) findings point to small $\beta$ s from individual interest to future knowledge and moderate $\beta$ s from proximal situational interest to future knowledge. Their mean-based, path modelling suggested the mediated impact of individual interest through situational interest as well as a small direct connection for future knowledge.

Recent reciprocal modelling of individual (Fryer \& Ainley, 2019) and situational (Nuutila et al., 2020) interest with students' prior and ongoing knowledge have indicated that knowledge is part of both initial readiness and the learning process. These findings are consistent with research that ties prior knowledge to interest and its development (see Durik \& Matarazzo, 2009; Hidi \& Renninger, 2006; Renninger \& Hidi, 2011; Renninger et al., 1992; Schiefele, 1991) and the well-established fact that prior knowledge can account for between 30-60\% of the variance of future learning (Tobias, 1994). Hence, because of these relations with the other readiness variables and the relation between prior knowledge and future learning, any modelling of the relations between prior Domain interest, Task interest, and developing Course and Domain interest needs to control for the effects of prior knowledge.

Self-efficacy is a forward-focused ability belief, describing an individual's perception of their ability to successfully complete a specific task (Bandura, 1997). While the majority of self-efficacy research has addressed task-level outcomes, Bandura (2011) has clarified that self-efficacy beliefs are also relevant for longer term pursuits such as skills development (e.g., teaching self-efficacy; Bandura, 1993) playing out over time and is not restricted to single events.

Self-efficacy is a critical component of students' readiness for task engagement. First, self-efficacy at the course level (Fryer et al., 2016) and at the task level (Nuutila et al., 2020) is a consistent longitudinal predictor of Task interest. Second, there is strong theoretical (Hidi et al., 2007) and empirical (Fryer \& Ainley, 2019; Nuutila et al., 2020) support for reciprocal linkages between self-efficacy and interest over time. Moreover, there is support for the unique contribution of both interest and self-efficacy to learning outcomes (Fryer \& Ainley, 2019; Nuutila et al., 2020). Self-efficacy is also consistently one of the strongest correlates of achievement in higher education (Richardson et al., 2012; Schneider \& Preckel, 2017) and 
education more broadly (Honicke \& Broadbent, 2016). Its impact on learning, hypothesised as being through persistence (Bandura, 1993), is robust even after applying rigorous controls for prior knowledge (Fryer \& Ainley, 2019; Nuutila et al., 2020).

The three components of readiness reviewed are certainly not exhaustive. However, the established theoretical and empirical linkages between these components of readiness and students' classroom task experiences support further investigation of their combined role within classroom-based interest development. Modelling the pattern of relations between readiness components of prior Domain interest, prior knowledge, and self-efficacy as they contribute to students' Task interest across a semester will provide further insight into interest development within formal classroom contexts.

\subsection{The current study}

The current study tested the unique contributions of students' task experiences for students' longer-term interest in a new domain. For a test of this kind to be meaningful, it was essential that students' readiness for tasks be accounted for and that all forward connections to and through Task to Course and Domain interest were tested.

To map these relations, a study was designed to record and identify the links between readiness variables, Task, Course and Domain interest across a mandatory short course for research postgraduate students, preparing them to conduct undergraduate tutorials. Across roughly four weeks, in eight modules (3 hours each), students engaged in a broad array of individual and group tasks, short lectures and reflections. Students' readiness for the course was assessed as prior knowledge, Domain interest and self-efficacy at the beginning of the first module of the course. Students' interest in seven representative tasks was collected immediately after each task, and formative evaluation of students' understanding of course materials was tested three times. During the seventh module students' interest in the course was collected (Course interest) and during the eighth and final module students' interest in the domain (Domain interest) was collected. For a graphical overview of the current study's research design, see Figure 1.

++++++++++++++++++++++FIGURE 1 ABOUT HERE+++++++++++++++++++++

\section{Aims}

The present study was designed to address three research questions and facilitate tests of five hypotheses. First, how do aspects of students' readiness predict their interest in a 
series of different course tasks, ongoing formative assessment, and their post Course and Domain interest (Research Question 1: RQ1)?

\section{Hypothesis1(H1)}

H1a: Based on the conceptual consistency and current modelling of interest development across a series of reengagements in a domain (Renninger \& Hidi, 2016), strong forward relationships were expected between prior Domain interest and Task interest and future Domain interest. Based on previous modelling with these levels of interest, a direct predictive relationship from prior Domain interest to Task interest and post Domain interest was expected. Due to potential mediation by Task interest and its unique constituent components (pairing of environment and content), prior Domain interest was not expected to directly predict Course interest, (e.g., see Fryer et al., 2016). H1b: Based on the substantial previous research connecting prior knowledge with future achievement, prior knowledge was expected to positively predict future formative assessments (Dochy et al., 1999).

\section{Hypothesis2(H2)}

Weaker and fewer inter-construct (e.g., interest - achievement), relative to intraconstruct (e.g., interest - interest) connections were expected. Prior self-efficacy due to its strong proximal engagement focus (Bandura, 1993) was expected to directly, positively predict future proximal Task, but neither Course nor future Domain interest (supported by two recent longitudinal studies with these levels of interest; Fryer et al., 2016, Fryer \& Bovee, 2020) (H2a). Prior self-efficacy, due to its theoretical focus (Bandura, 1993) on and consistently strong empirical relationship with achievement (Richardson et al., 2012), was expected to positively predict future formative assessment (Fryer \& Ainley, 2019; Honicke \& Broadbent, 2016; Nuutila et al., 2020) (H2b). Based on interest's capacity to support learner persistence (Renninger \& Hidi, 2016) and recent studies consistent with this study's design, interest (Task and prior Domain) were expected to positively predict future formative assessment (Fryer \& Ainley, 2019; Nuutila et al., 2020; Rotgans \& Schmidt, 2018) (H2c). Prior knowledge was expected to positively predict interest (Renninger \& Hidi, 2016; Tobias, 1994). Recent modelling (Fryer \& Bovee, 2020) and the unique composite nature of Course interest discussed to this point, however, suggested no significant direct predictive relationship in the specific case of Course interest (H2d). There is empirical support for prior knowledge to directly, positively predict future Domain interest (Fryer \& Ainley, 2019) (H2e) and positively predict future Task interest (Nuutila et al., 2020) (H2f).

Second, how do Task interest experiences predict each other, future formative tests, and build towards longer-term Course and Domain interest (Research Question 2: RQ2)? 


\section{Hypothesis3(H3)}

Based on theory indicating that interest can drive student engagement (Renninger \& Hidi, 2016) and recent empirical evidence (Fryer et al., 2016; Nuutila et al. 2018, 2020; Rotgans \& Schmidt, 2018), modelling was expected to present strong predictions between proximal measures of Task interest.

\section{Hypothesis4(H4)}

Due to potential mediation (Course - Domain interest) and the specific composite nature of Course interest (i.e., environmental and content components), Task interest was expected to strongly directly predict Course interest, but not Domain interest directly (consistent with Fryer et al., 2016).

\section{Hypothesis5(H5)}

Based on longstanding theory suggesting developmental relationships between interest and knowledge (Alexander, 2003; Renninger \& Hidi, 2016) and recent empirical evidence (Nuutila et al., 2020), direct positive predictive relationships were expected both from Task interest to future formative assessment outcomes and from formative assessment outcomes to future Task interest (i.e., a reciprocal relationship).

The final research question was exploratory and aimed at beginning to address how the social valence of classroom tasks might specifically affect future interest at different levels: How might the social nature of the tasks impact the web of connections into, across and forward, beginning with readiness to and through each Task, Course and Domain interest (RQ3)? To enable an exploratory assessment of the social nature of the Tasks, a comparison of the interest experienced in three task types was undertaken: large group discussion (Task1, Task5), paired (Task7), individual (Task2, Task3) and individual then followed by small group (Task4, Task6). A hypothesis could not be confidently constructed due to a lack of detailed theorising and empirical research in this area. However, theory (Bergin, 1999, 2016; Bergin et al., 2013) and pilot research for the current study point toward the particularly important forward contribution of socially orientated (large group or entire class) classroom tasks and opportunities to demonstrate competence publicly and experience interest vicariously (as part of a large group). In the current mapping exercise, this lens will be used in review to examine these task categories for potential patterns that might support further research in this area. 


\section{Methods}

\subsection{Participants}

The current study was undertaken in a mandatory teaching course preparing research postgraduate students for undergraduate tutorial responsibilities. Research postgraduate students from all 10 of the university's faculties ( $n=322$ invited; $n=310$ participated, Female $=148$, Male=151; Prefer not to say/Non-binary=11) participated in the study. Precise demographics for this sample were not included in the ethics proposal but demographics for the programme of courses that academic year $(n=564)$, of which the later half was the present sample were as follows: Hong Kong residents (17.2\%), Mainland Chinese (72.3\%), other countries (10.5\%); Ages 22-26.

\subsection{Procedures}

Prior to starting the current study, the project was reviewed by the university's Institutional Review Board and permission to proceed was granted. Before the study began, all participants were informed of the project's aims, that participation was voluntary, that the data they contributed were anonymous and that they were free to withdraw at any stage. Informed consent was collected using mobile devices at the beginning of the first class of the course being researched.

The current research was conducted in 17 short courses ( $n=16-22$ each). The courses were designed to support students in undertaking teaching assistantships at the university during their candidacy. The course consisted of eight modules; each three hours long completed over four weeks-two modules a week. The course consisted of readings, short lectures, paired and group activities. Students conducted two micro-teaching sessions (10 and 15 minutes long) and received feedback from peers and the instructor. The courses were split and taught by two course teachers, each following the same curriculum and utilising the same teaching and learning materials (classroom activities, assessments, printed materials, readings, videos and slides).

Data were collected via a bespoke HTML5 website designed solely for the collection of self-reported data with touch devices (Fryer \& Fryer; 2019; Fryer \& Nakao, 2020). Students captured a QR-code embedded in course materials (usually slides) leading them to the website for anonymously providing self-reported interest and self-efficacy measures, as well as completing prior knowledge and formative tests. Formative tests were conducted at the beginning or end of classes. Task interest surveys were conducted immediately after completing the respective task being assessed for the interest it stimulated. Task surveys took 
between 18 and 78 seconds to complete. The surveys were generally faster to complete as the course progressed as students grew accustomed to the software's interface (Fryer \& Nakao, 2020).

The overall research design is presented in Figure 1. Tasks were strategically selected for interest measurement, aiming for both a wide variety of levels of social interaction (solo, paired and group) and types of engagement (reading, listening, discussion, writing and combinations of these). An overview of each of the tasks assessed by the current research is presented in Table 1 (Appendix), Figures 1 and 2 indicate the task types for quick reference in interpreting the study's findings.

\subsection{Instrumentation}

Consistent with Kosovich et al. (2017), this study aimed to balance quality of measurement with the pragmatic realities (time and convenience) of conducting microanalytic research during class time. To this end, scales were shortened while striving to maintain their predictive and construct validity, and reliability.

Three levels of interest (Task, Course and Domain) were measured across the course, along with a measure of self-efficacy beliefs at the course level (i.e., consistent with the course's skills development aims), tests of prior knowledge and three formative tests (see supplemental materials, Table 5) were employed in the current research. The Task interest scale was three items in length and drew on items from past Task interest-orientated research where it had presented robust reliability and construct validity (Fryer et al., 2016, 2017, 2019, 2020; Fryer \& Bovee, 2020; Fryer \& Nakao 2020): a) This task was interesting; b) This task was personally meaningful; c) I want to learn by doing tasks like this. The Course interest scale was also drawn from the same past research and also consisted of three items: a) This course is interesting; b) This course is personally meaningful; c) I want to learn more in courses like this. Both scales utilised a six-point response scale from 0-Nothing Like Me to 5Exactly Like Me.

The pre/post Domain interest scale (Renninger \& Schofield, 2014) was used recently in four longitudinal studies conducted within university foundation courses as a pilot to the current study. Based on the previous use of the scale and consistent with making the instrument unobtrusive, three items were selected for use in the current study. Items were selected based on their content (epistemologically and behaviourally-orientated focus, consistent with reengagement with the domain), individual factor loading, and reliablity/predictive validity as a whole. The three items selected for the pre-post measure: 1) 
How much do you know about teaching?; 2) In your spare time, how often have you tried to learn about teaching?; 3) I have spent time learning about teaching on my own.; Item 3 was preceded by "How well does this statement match you?" All items were measured across a six-point cumulative response scale: For Item \#1 Almost Nothing-Almost Everything, for item \#2 Almost Never-Almost Always and for \#3 Not at all-Completely.

The prior knowledge test was developed by the course instructors who were best situated to determine what constituted important prior knowledge for the subsequent course of study. The prior knowledge assessment (six items) and the formative assessments (six items each) were all multiple choice to ensure consistent and quick feedback to the students immediately after completion (See supplemental materials, Table 5).

To assess students' initial self-efficacy for the course, teacher self-efficacy, Tschannen-Moran and Hoy's (2001) Teachers' Sense of Efficacy Scale (TSES) was used. Research correlating the TSES (from teachers) and with self-reported student experiences has indicated that teacher's self-efficacy is associated with their teaching performance (Klassen \& Tze, 2014). In higher education, teaching self-efficacy is associated with a student-focused approach to teaching (Kaye \& Brewer, 2013). Four items from the Teachers' Sense of Efficacy Scale (e.g., I can craft good questions for students.) were used. These items had recently been used in the same research context (Shum et al., 2020) and exhibited robust construct validity, reliability and predictive power. All items were assessed across a scale of $0-5$, from nothing like me to exactly like me. The items themselves were congruent with the course's content and its intended learning outcomes. All items for all survey scales are presented in Appendices (Table 6)

\subsection{Analyses}

Analyses proceeded in four stages. The first stage was not central to the study's questions/hypotheses, but was important to briefly review the means, standard deviations and reliability of the latent measures (Raykov's Rho; Raykov, 2009) and to ascertain the potential effect of the course on students' interest in the domain (paired $t$-test of pre-post Domain interest). Second, convergent and divergent validity of the latent constructs were assessed by conducting pairwise correlations and Confirmatory Factor Analyses (CFA) of all latent variables together. Third, invariance testing was conducted, first for pre-post Domain interest and then for Task interest. Finally, addressing this study's research questions and hypotheses, a fully-forward latent model test was conducted (RQ1,2,3; H1,2,3,4,5). A fully-forward 
model test is a test of all variables predicting all future variables with no pathways removed to improve fit.

All latent modelling was undertaken with Mplus 7.0 (Muthén \& Muthén, 2014). Missing data were $8 \%$, which is acceptable given the complexity of the design (during class and spanning multiple courses) and micro-analytic (on task and short) nature of the data collection. The missing data were chiefly due to students missing class or arriving late. Missing data were resolved through the Full Information Maximum Likelihood method (Enders, 2010).

For all structural equation modelling, the nested quality of the data (i.e., students in 17 different courses) was accounted for using cluster-robust standard errors with Mplus (Muthén \& Muthén, 2014). For this analysis, each individual course group was treated as a cluster. This approach was used because the number of level two clusters was insufficient to prevent bias (i.e., < 50; Maas \& Hox, 2005).

Structural models were assessed using four fit indices. Root Mean Square Error of Approximation (RMSEA), with values below .08 and .05 indicating acceptable and good fit respectively (Browne \& Cudeck, 1992), Tucker Lewis Index/Confirmatory Fit Index (TLI/CFI) with values above .90 and .95 indicating acceptable and good fit respectively (Marsh, Balla, \& McDonald, 1988), and Standardized Root Mean Square Residual (SRMR) where values less than .08 are generally considered a good fit (Hu \& Bentler, 1999).

Invariance testing in the present study followed Marsh et al.,'s (2013) example. Invariance testing of Task interest (Task 1-7) and Domain interest (pre-post) used CFI and RMSEA comparisons to assess the adequacy of the invariance across the study. Chen (2007) contended that the assumption of invariance is tenable if CFI does not change by greater than .01 and the RMSEA increases no more than .015 for the invariant model.

For modelling of the type pursued in the current study, statistical significance, is a useful, but weak heuristic; as a result, effect sizes are the focus of the study's results and discussion. With this in mind, Keith's (2015) guidelines for interpreting beta coefficients in research on learning influences were used, suggesting that standardised betas below .05 should be interpreted as 'too small to be considered meaningful'; those above .05 should be considered 'small but meaningful'; those above .10 should be considered 'moderate'; and those above .25 should be considered 'large'. 


\section{Results}

\subsection{Descriptive statistics, reliability and pairwise correlations}

Table 2 presents the means, standard deviations, Raykov's Rho and the pairwise correlations for all variables in the present study. The reliabilities for all scales were well above the standard cut-off for acceptable (>.70; Devellis, 2012). Pairwise correlations were consistent with past research connecting interest, self-efficacy beliefs, prior knowledge and formative assessments.

-Table 2 about here

Comparison of Domain interest across the study indicated a large increase across the course $(t(309)=25.83$, Large Cohen's $d=2.07)$.

\subsection{Structural Equation Modelling}

Fit for each of the four models tested is presented in Table 3. Based on the model fit guidelines presented for invariance tests, the assumption of invariance for both the Task and Domain interest was deemed tenable. Fit for both the configural and fully-forward final models presented excellent fit for all four heuristics referenced.

-Table 3 about here-

Figure 2 presents the final model in full. The modelling results will be reviewed in concert with this study's research questions and hypotheses. While statistically significant $(p<.05)$ predictions will be the focus of the main results and discussion, all significant and nonsignificant tested pathways are presented in Figure 2, and all $\beta \mathrm{s}$, significant and nonsignificant, are presented in the Appendices in Table 4.

Figure 2 about here

Prior to reviewing the forward connections, correlations between prior variables should be acknowledged (no hypotheses set). Prior knowledge presented small $(p<.05)$ relationships with prior Domain interest and self-efficacy ( $r=.09, .04$ respectively). Prior Domain interest and self-efficacy presented a strong relationship ( $r=.67)$.

Providing support for H1, prior Domain interest presented significant predictive direct relationships with just one Task interest (H1a: Task6, $\beta=.25)$ and post Domain interest (H1a: $\beta=.24$ ), but not future Course interest (H1a: $\beta=-.02, p=.53$ ). Prior knowledge directly predicted all three formative assessments $(\mathrm{H} 1 \mathrm{~b})$ : Module2 test $(\beta=.11)$, Module5 test $(\beta=.24)$ and Module6 test $(\beta=.11)$.

Consistent with $\mathrm{H} 2$, prior self-efficacy presented three significant predictive relationships (H2a) with future interest: Task1 $(\beta=.18)$, Task3 $(\beta=.14)$, but did not 
significantly predict future Course interest $(\beta=.06, p=.32)$. Inconsistent with $\mathrm{H} 2 \mathrm{a}$, however, prior self-efficacy presented a moderate negative relationship with post Domain interest ( $\beta=-.13$ ). Consistent with $\mathrm{H} 2 \mathrm{~b}$, prior self-efficacy significantly predicted the first formative assessment (Module2 test, $\beta=.18$ ), but not the other formative tests. The modelling results presented mixed support for $\mathrm{H} 2 \mathrm{c}$. Just two Task interest variables made significant direct contributions to Module6 test: Task3 positive $(\beta=.31)$ and Task4 negative $(\beta=-.21)$, but prior Domain interest did not present a statistically significant $\beta$ for any future formative test.

Prior knowledge failed to significantly predict future Course interest $(\mathrm{H} 2 \mathrm{~d}$, consistent), Domain interest (H2e, inconsistent) and Task interest (H2f, inconsistent).

Consistent with $\mathrm{H} 3$, Task interest was strongly connected, particularly with the interest in the subsequent two tasks (H3) and strongly connected to Course interest (see Figure 2; H4). Contrary to H4, Task interest also directly predicted Domain interest: Task3 interest $(\beta=.10)$ and Task5 interest $(\beta=.15)$.

Inconsistent with $\mathrm{H} 5$, no statistically significant reciprocal relationships between Task interest and formative tests were apparent (H5).

\section{Discussion}

This study mapped the interconnections between students' readiness for a mandatory introductory course, to and through their interest in a series of tasks, formative assessments, and on to their interest in the course and then their interest in the broader domain of study.

\subsection{Research Questions and Hypotheses}

Three broad research questions were addressed, with the first two framing five hypotheses that were tested by the longitudinal latent structural equation model (Figure 2). Initial difference tests confirmed that students' Domain interest increased dramatically across the short course, suggesting that the intensive introduction to teaching was helping students develop a lasting interest in teaching.

RQ1: How do aspects of students' readiness predict their interest in course tasks, formative assessment performance, and post Course and Domain interest?

Partially confirming expectations of robust forward relationships between conceptually close variables (H1), prior Domain interest predicted Task interest (Task6, Marking Activity) and post Domain interest, with moderate and large effect sizes, but no formative assessment outcomes (H2). Consistent with expectations (H1) prior knowledge 
predicted all future formative assessments with moderate $\beta \mathrm{s}$, but no other future constructs (H2). The final aspect of readiness examined presented the most cross-theoretical connections, generally confirming our expectations $(\mathrm{H} 2)$ : self-efficacy presented moderate $\beta \mathrm{s}$ for proximal Tasks' interest (Task1, Task3), supporting past evidence linking it to task experiences (Fryer et al., 2016); self-efficacy presented the strongest $\beta$ for the first formative test (H2). In an unexpected model outcome, self-efficacy also presented a moderate negative $\beta$ for post Domain interest (H2).

RQ2: How do interest in task experiences predict each other, future formative test outcomes, and build towards longer-term Course and Domain interest?

Strong interconnections between proximal Task interest were present (H3). With the exception of Task6, each measure of Task interest significantly predicted (large $\beta \mathrm{s}$ ) Task interest in the next task. For Task1, Task2, Task3 and $5 \beta$ s were significant in the subsequent two tasks wherein interest was assessed. As expected, Task interest (Task3, Task5, Task6) was a strong direct, large predictor of Course interest (H4). Unexpected were the additional ubiquitous direct moderate $\beta$ s from Task interest to Domain interest (Task3, Task4, Task5; H4). Inconsistent with H5, no statistically significant reciprocal connections between any of the Task interest and formative assessments were observed. RQ3 (Exploratory): How might the social nature of the tasks impact the web of connections into, and across Tasks, Course and Domain interest?

The pattern of the connections to and through the tasks (Figure 2) suggested no clear differences from readiness to the tasks with a clear social valence (RQ3). Prior teacher selfefficacy predicted proximal Task interest for tasks which demanded active engagement (i.e., discussion Task1; individual writing activity, Task3). Prior Domain interest presented a large $\beta$ for the Task interest for the most practical task of the course (marking actual past tutorial tasks, Task6) but not Task interest (Task1 and Task5) with a clear social valence. Task3 (the least social task; individual writing task) interest presented the most direct predictions for future Task, Course and Domain interest, and a formative test outcome (Module6 test). There were also findings that were consistent with substantial research connecting social experiences and interest development (Bergin, 2016; Bergin et al., 2013). For example, interest in both of the discussion tasks (Task1, Task5) were substantial predictors of future Task interest. Consistent with pilot findings, Task5's interest (exclusively focused on group discussion) presented the strongest overall Task interest $\beta$ for students' Course and post Domain interest. 
For the majority of the non-significant $\beta$ s that could have been expected given theory and/or past research, mediation is the most likely reason: for example, Task1 interest predicting Task4-7 interest, future Course or Domain interest. In other cases, the lack of significant linkages might be attributed to the introductory nature of the course, students' lack of experience, and perhaps not knowing what to expect: for example, prior Domain interest failure to predict Task1-5, 7 interest or prior knowledge's failure to predict future interest at any level assessed. Finally, while it might have been expected that students' performance on formative tests would present statistically significant $\beta$ s going forward, this lack was likely due to the very different, modularised content assessed.

\subsection{Implications for Theory}

\subsubsection{Students' Readiness}

Prior Domain interest presented significant $\beta$ s for Task interest in just one case in addition to the auto-lagged connection to Post Domain interest. The Task interest predicted was for one of the most practical course activities students engaged in during the course (Task6). In this task, students marked actual past assignments from past tutorial students and compared their marks with past tutors. This strong, singular connection, suggested that students interested in teaching, wanted hands on practice, something they could concretely identify as real teaching. More interested students were ambivalent about the standard course curricula (e.g., reading, written exercises), but as we would expect remained more interested in the domain at the end of the course.

In contrast to prior Domain interest, students' initial self-efficacy for teaching was an important predictor of interest in two of the course's early tasks (as in Fryer et al., 2016). Prior self-efficacy's direct prediction of performance on the first formative test points to its robust proximal role within learning experiences and is consistent with theory (Bandura, 1993; Honicke \& Broadbent, 2016). Prior self-efficacy's negative $\beta$ for post Domain interest while seemingly counter-intuitive, is actually consistent with the course and its aim in giving students a crash course in teaching: Supporting novice teachers (i.e., lower self-efficacy for teaching) in developing a lasting interest in teaching.

\subsubsection{Connecting Task Experiences}

The large, consistent connections between interest in the proximal tasks assessed is in alignment with both theory framing interest as a desire to reengage which sets up the reciprocal support for interest development across time (Renninger \& Hidi, 2016). A considerable body of research in the area of interest measured at the task level also supports 
these connections (e.g., Fryer et al., 2016; Nuutila et al., 2020; Rotgans \& Schmidt, 2018). In most cases, Task interest presented a substantial $\beta$ for interest in the next two tasks. The only task to miss a pairing of potential proximal incoming and outgoing $\beta$ s to other tasks was the course's most practical and realistic task (marking past assignments; Task6). Interest in this task was also the only one predicted by prior Domain interest. Both the type of cognitive engagement the task demanded (interpretation and evaluation) and its very practical nature likely played a role in this outcome.

Compared to past research organising interest across a repeated task (i.e., a series of group quizzes) during a university course (Fryer et al., 2016), the present study demonstrates that some task experiences can make a direct contribution to both Course and Domain interest. Two types (discussion and individually completed activities) of tasks contrasted strongly here suggesting that the nature of the task content might play significant and complex roles in interest outcomes. Tasks consistent with the course's goals, but not socially engaging (individual written activity; e.g., Task3) might stimulate interest in the course (and potentially thereby the domain), but at the same time be directly connected to a decline in interest in the domain. The present modelling also suggests that interest in some tasks can directly predict just Domain interest, as well as, or instead of only having a connection to Course interest. Students might have perceived the written task (Task3) as being an additional, over structured and extraneous reading task. Students might have seen the task as important for the course (i.e., intro course on teaching) but not directly related to the domain of study (i.e., teaching). This type of perceived alignment is critical consideration for maximising instructional impact (Fryer et al., 2017; Boekaerts, 1999).

Task interest only predicted one of the three formative tests. Given that this formative test (Module 6) was predicted by prior knowledge in a manner consistent with the first two formative tests, there is no reason to think it was any more challenging or in any way aberrant. Students interested in the individual writing task did better and students interested in the reading and paired sharing task fared worse. As the content of the test was not consistent with either of the tasks, it suggests that the students' interest in the contrasting nature of the different tasks played a role in their preparation for the test.

Examining the potential contribution of the tasks' varying degrees of social components (i.e., individual, individual-then-small group, paired, large group discussion) for future interest presented no clearly contrasting pattern to support deductive conclusions. There is some evidence to support an outsized role for large group discussions for future Task, Course and Domain interest (i.e., Task5). It is reasonable to postulate that the public 
performance (Bergin, 2013) and vicarious elements (Bergin, 1999) of these discussions contributed to the positive forward relationships seen in this study and in previous pilot research with these levels of interest specificity (Fryer et al., 2017). It is important to point out that the social nature of these types of tasks alone is unlikely to be sufficient; Clear task structure (e.g., Task6, cases analyses) and outcomes (e.g., Task3, comparisons of knowledge levels) are likely also important factors (Skinner, 1995).

\subsection{Implications for Practice}

Implications for practice must be considered in light of the nature of the course: A compulsory, introductory course in teaching for postgraduate students from 10 different faculties. As a result, students often come with low prior knowledge, self-efficacy and a wide range of interest (quantity and quality) in the course and domain of study. This kind of introductory learning environment and its resulting student profiles is not rare at university, and can be some of the most difficult to effectively engage students in. With this in mind, three clear practical implications from this study's results are worth reviewing.

The first is the role of initial self-efficacy for the course of study. Students who are more confident in their ability to successfully engage with the course content (i.e., how to teach) are more interested in the early course tasks and perform better on early formative tests-in contrast to prior Domain interest's lack of statistically significant role. The pattern of Task interest connections modelled makes it clear how important each and every task can be and how they build interest across the course. The question is how can instructors do anything about initial self-efficacy beliefs? After all, it is the first class, instructors do not know the students, there is limited opportunity to support students' self-efficacy through the standard means suggested by socio-cognitive theory (e.g., mastery or vicarious experiences; Bandura, 1993, 1997), and these take time. An alternative route of initial support is suggested by broadening from self-efficacy to perceived control (Skinner et al., 1998); self-efficacy is one type of perceived control (Skinner, 1996). Perceived control is supported by structure, which at the beginning of the course is mostly clear communication of teacher expectations and the fundamental goals, and organisation of the course (Skinner, 1995). This communication about the course structure and expectations helps students understand the demands of the course and how to work towards them, potentially providing a path to enhancing their self-efficacy for the course of study right away.

Second, the present study suggests that students who come to a course with interest (ready to reengage) are likely to find clearly practical tasks interesting. Relevance is an 
important part of interest and its development particularly at later phases (Hidi \& Renninger, 2006; Renninger \& Hidi, 2011). A growing body of utility-value interventions (e.g., Canning \& Harackiewicz, 2019; Hulleman et al., 2010) has come from the other direction, helping students to understand how relevant their studies are, seeking to increase interest in them. In a university course context with a diverse array of initial levels of interest, engaging already interested students is just as important as engaging students less so.

Third, of the wide range of task interest types assessed in the current study, only large group structured discussion (Task5: Case Analyses) significantly predicted both Course and Domain interest positively. Providing students with opportunities for vicarious interest and public demonstrations of knowledge are well-established keys to interest development across formal education (Bergin, 2013, 2016). The current study demonstrated that these experiences can have impact across a wide variety of university courses, through supporting interest in the course and directly on individual interest. Every course at university should provide engagements of this kind, to ensure students' interest continues to develop. The only caveat to this suggestion might be to ensure groups are large enough to feel public, but small enough to ensure everyone has an opportunity to engage both personally and vicariously.

It is worthwhile considering how different task experiences might impact students' preparation for future learning. In the current course, some readings were done during class, while others were assigned for homework. The latter type was the focus of formative tests, which were used to encourage completion of homework assignments. As the content for Task4 in class reading and the Module6 test were unconnected, one hypothesis for the negative connection is that students who preferred in class reading, were less likely to do the out of class readings. As a result, they might have been less prepared for the formative test. This situation might be remedied by scaffolding the outside class reading experiences by engaging students in solo reading in stages: In class, then blended, then solo. Especially as the domain was entirely new, students might not have been confident in engaging with them alone, preferring instead to do it with the class, with the instructor present. For adult (in this case research postgraduate) students, this lack of readiness for independent reading might easily be overlooked.

Not every task needs to drive Domain interest directly, some important tasks might even be directly related to lower long-term interest (as seen with Task3: Organising verbs in appropriate learning levels). Their positive contribution might be mediated through other tasks, interest in the course and growing understanding of the content. The current study suggests that a balance of "heads-down" individual, paired and large-group discussions can 
go a long way towards supporting interest and knowledge in a new domain of study, for students with a wide variety of initial readiness.

Readiness as framed and modelled in the current study offers an initial sense of the complex role the composite construct plays. The components assessed here were not exhaustive but covered key aspects for establishing students' initial willingness and ability to effectively engage in a course of study. Broadly speaking, the components of readiness modelled impacted the learning experience in theoretically consistent ways: For example, greater prior knowledge predicted higher future test scores. However, modelling also highlighted the challenges of matching readiness with course curricula. Introductory courses like the context for this study might not appeal to students with higher prior self-efficacy for course content (i.e., related to lower post Domain interest). Readiness is clearly not a simple, broad "more is better" ingredient for course learning. Course instructors need to think carefully about how course contents are likely to engage (or fail to engage) students. Instructors either need to be sure that the match between curriculum and student readiness is robust by carefully selecting students (rarely possible) or ensuring that elements of the course can be personalised to fit a diverse array of student readiness for learning in the course.

\section{Limitations and Future directions}

One of the broad aims of this study was to establish a detailed map from critical components of learner readiness to and through task experiences, on to a lasting desire to reengage with the domain of study. While a map of interest experiences has been drawn for the course researched here, subsequent studies will be necessary to secure clear external validity for the pattern of findings presented.

The forward relationships from interest in three tasks remains partially unexplained and deserves attention from future research. The first is the negative relationship between Task4 interest and the Module6 formative test. How does specific Task interest connect with proximal learning is a budding research area supporting positive connections (e.g., Nuutila et al., 2020), but not negative relationships? The complicated web of connections between Task interest and learning deserves further research. The second question raised by the current study is how a task experience might be positively connected to all proximal tasks and Course interest, but negatively directly linked to Domain interest. This type of complex interplay of situational and individual interest needs further theorising and fine-grained research. The final Task interest related question arising from this research originates from the lack of forward connections from Task7 (i.e., revisiting feedback from other students) 
interest. Reflection is an essential part of the learning process (Daudelin, 1996) and certainly plays a critical role in the development of important self-beliefs. That said, despite its proximity to the Course interest measurement, it failed to present even a small forward connection. The role of reflection within interest has not to our knowledge been the focus of interest development research. We believe it deserves some attention, with a specific focus on how it might or might not affect future interest and how to best structure reflection to promote interest development.

The singular connection from prior Domain interest to the course's most practical Task's interest (Task6) is worthy of more investigation. It might be that this kind of singular focus for initial interest is specific to introductory, skills-based courses like the one under research here. Further research is necessary to test this hypothesis.

Contrary to past research using the same course-based measures of interest (e.g., Fryer et al., 2016), interest in two of the tasks presented forward connections to both Course and Domain interest-past research suggested Course interest entirely mediated Task interest experiences on Domain interest. The current finding confirms that Course interest (a collation of interest in the course learning environment and interest in the content of the course; Hoffman, 2002) and Domain interest (individual interest in the broader domain of study) are conceptually and empirically different and should be assessed separately in research like that presented here. It also suggests that some tasks can straddle these types of interest driving them both positively (Task5 interest) or in different directions (Task3 interest). How the content (e.g., Topic interest: Ainley et al., 2002; Hoffman, 2002) and structure of tasks makes this possible is an area in need of additional research.

\section{Conclusions}

In an introduction to teaching course for research postgraduate students, the fullyforward network of relationships between students' readiness, knowledge development, Task and Course interest experiences on course-end Domain interest was tested. Framing this study is evidence suggesting that the course was strongly supporting students in developing interest in the domain of study. Specific modelling findings confirmed the role of selfefficacy for the course of study as an important source of support (i.e., a "kickstart") for early task experiences and knowledge development. Prior interest in this introductory course context presented a solitary connection to one explicitly practical, authentic task, suggesting what initially interested students want from courses of this type. Results emphasise the diverse and potentially outsized contributions of intensive task experiences that are heads- 
down individual or large-group discussion based. The strong forward connections of the ends of this classroom task type continuum demonstrate how the structure of individual tasks can play a large role in both course experiences and the long-term interest students leave them with. The present study aimed to map students' interest experiences from readiness, to tasks and tests, to interest in the course and domain moving forward. The resulting model established clear levels of measurement and a preliminary set of findings to guide future studies in understanding how students get interested in new domains across a university course experience. 


\section{Reference}

Ainley, M. (2017). Interest: Knowns, Unknowns, and Basic Processes. In P.A. O'Keefe \& J. M. Harackiewicz (Eds.), The Science of Interest (pp. 3-24). Cham: Springer International Publishing.

Ainley, M., Hidi, S., \& Berndorff, D. (2002). Interest, learning, and the psychological processes that mediate their relationship. Journal of Educational Psychology, 94, 545-561. http://doi.org/10.1037//0022-0663.94.3.545

Azevedo, F.S. (2013). Knowing the stability of model rockets: A study of learning in interest-based practices. Cognition and Instruction, 31, 345-374. http://doi.org/10.1080/07370008.2013.799168

Alexander, P. (2003). The development of expertise: The journey from acclimation to proficiency. Educational Researcher. 32, 10-14. https://doi/abs/10.3102/0013189x032008010

Bandura, A. (1993). Perceived self-efficacy in cognitive development and functioning. Educational Psychologist, 28, 117-148. https://doi.org/10.1207/s15326985ep2802_3.

Bandura, A. (1997). Self-efficacy: The exercise of control. New York: Freeman.

Bandura, A. (2011). On the functional properties of perceived self-efficacy revisited. Journal of Management, 38, 9-44. https://doi.org/10.1177/0149206311410606.

Bergin, D.A. (1999). Influences on classroom interest. Educational Psychologist, 34, 87-98. doi: https://doi.org/10.1207/s15326985ep3402_2

Bergin, D.A., Bergin, C., Van Dover, T., \& Murphy, B. (2013). Learn more: Show what you know. Phi Delta Kappan, 95, 54-60. http://doi.org/10.1177/003172171309500110

Bergin, D.A. (2016). Social Influences on Interest. Educational Psychologist, 51, 7-22. http://doi.org/10.1080/00461520.2015.1133306

Boekaerts, M. (1999). Motivated learning: Studying student-situation transactional units. European Journal of Psychology in Education, 14, 41-55.

Browne, M., \& Cudeck, R. (1992). Alternative ways of assessing model fit. Sociological Methods \& Research, 21, 230-258. https://doi.org/10.1177/0049124192021002005

Burnette, J.L., Hoyt, C.L., Russell, V.M., Lawson, B., Dweck, C.S., \& Finkel, E. (2020). A Growth mind-set intervention improves interest but not academic performance in the field of computer science. Social Psychological and Personality Science, 11, 107116. http://doi.org/10.1177/1948550619841631

Canning, E.A., \& Harackiewicz, J.M. (2019). Utility Value and Intervention Framing. In Cambridge Handbooks in Psychology (1st ed., Vol. 8, pp. 645-662). Cambridge University Press. http://doi.org/10.1017/9781316823279.027

Cavanagh, M. (2011). Students' experiences of active engagement through cooperative learning activities in lectures. Active Learning in Higher Education, 12, 23-33. http://doi.org/10.1177/1469787410387724

Chen, J.A., Tutwiler, M.S., Metcalf, S.J., Kamarainen, A., Grotzer, T., \& Dede, C. (2016). A multi-user virtual environment to support students' self-efficacy and interest in science: A latent growth model analysis. Learning and Instruction, 41, 11-22. http://doi.org/10.1016/j.learninstruc.2015.09.007

Devellis, R.F. (2012). Scale Development: Theory and application (3rd ed.). Thousand Oaks, CA: Sage.

Dewey, J. (1913). Interest and effort in education. Boston: Houghton Mifflin Company.

Daudelin, W.M. (1996). Learning from experience through reflection. Organizational Dynamics, 24(3), 36-48. doi: https://doi.org/10.1016/S0090-2616(96)90004-2 
Dochy, F., Segers, M., \& Buehl, M.M. (1999). The relation between assessment practices and outcomes of studies: The case of research on prior knowledge. Review of educational research, 69(2), 145-186.

Durik, A.M., \& Matarazzo, K.L. (2009). Revved up or turned off? How domain knowledge changes the relationship between perceived task complexity and task interest. Learning and Individual Differences, 19, 155-159. http://doi.org/ 10.1016/j.lindif.2008.08.005

Enders, C.K. (2010). Applied missing data analysis. New York: Guilford Press

Fryer, L. K., Thompson, A., Nakao, K., Howarth, M., \& Gallacher, A. (2020). Supporting selfefficacy beliefs and interest as educational inputs and outcomes: Framing AI and Human partnered task experience. Learning and Individual Differences. https://doi.org/10.1016/j.lindif.2020.101850

Fryer, L. K., \& Bovee, H. N. (2020) Teaching for course interest. Studies in Higher Education. https://doi.org/10.1080/03075079.2020.1712692

Fryer, L. K. \& Nakao, K. (2020). The Future of Survey Self-report: An experimental test of Likert, VAS, Slide, \& "Swipe" touch interfaces. FrontLine Learning Research. https://doi.org/10.14786/flr.v8i2.502

Shum, A., Lau, P. \& Fryer L. K. (2020) From learner to teacher: (re)training graduate teaching assistants' teaching approaches and developing self-efficacy for and interest in teaching, Higher Education Research \& Development, https://doi.org/10.1080/07294360.2020.1818063

Fryer, L. K., Nakao, K. \& Thompson, A. (2019). Chatbot learning partners: Connecting learning experiences, interest and competence. Computers in Human Behaviour. 93,279-289. https://doi.org/ 10.1016/j.chb.2018.12.023

Fryer, L. K. \& Fryer, K. (2019, Sept 19). 情報処理装置、情報プログラムおよびこれを 記録した記録媒体、ならびに情報 処理方法. Patent application \# 2017-165970;

Patent \# 6585129 (Japan).

[Dynamic touch-based interface for survey self-report; Translation of Japanese patent title: information processor (information technology equipment), information program and a medium for the recording, and a method of information processing]

Fryer, L. K., Ainley, M., Thompson, A., Gibson, A., \& Sherlock, Z. (2017). Stimulating and sustaining interest in a language course: An experimental comparison of Chatbot and Human task partners. Computers in Human Behavior, 75, 461-468. https://doi.org/10.1016/j.chb.2017.05.045

Fryer, L. K., Ainley, M. \& Thompson, A. (2016). Modelling the links between students' interest in a domain, the tasks they experience and their interest in a course: Isn't interest what university is all about? Learning and Individual differences. 50, 57-165 https://doi.org/10.1016/j.lindif.2016.08.011

Grigg, S., Perera, H.N., McIlveen, P., \& Svetleff, Z. (2018). Relations among math Self-efficacy, interest, intentions, and achievement: A social cognitive perspective. Contemporary Educational Psychology, 53, 73-86. http://doi.org/10.1016/j.cedpsych.2018.01.007

Harackiewicz, J.M., Smith, J.L., \& Priniski, S.J. (2016). Interest Matters: The Importance of Promoting Interest in Education. Policy Insights from the Behavioral and Brain Sciences, 1-8. http://doi.org/10.1177/2372732216655542

Hazari, Z., Potvin, G., Cribbs, J.D., Godwin, A., Scott, T.D., \& Klotz, L. (2017). Interest in STEM is contagious for students in biology, chemistry, and physics classes. Science Advances, 3(8), e1700046. doi:10.1126/sciadv.1700046

Hidi, S. (1990). Interest and its contribution as a mental resource for learning.

Review of Educational Research, 60(4), 549571.

https://doi.org/10.3102/00346543060004549 
Hidi, S., \& Anderson, V. (1992). Situational interest and its impact on reading and expository writing. The role of interest in learning and development, 11, 213-214.

Hidi, S., \& Renninger, K. (2006). The four-phase model of interest development. Educational Psychologist, 41, 111-127. doi:10.1207/s15326985ep4102_4

Hidi, S., Ainley, M., Berndorff, D., and Del Favero, L. (2007). "The role of interest and selfefficacy in science-related expository writing," in Writing and Motivation, eds S.Hidi, and P. Boscolo (Oxford: Elsevier), 203-217. http://doi.org/ 10.1108/s15726304(2006)0000019013

Honicke, T., \& Broadbent, J. (2016). The influence of academic self-efficacy on academic performance: A systematic review. Educational Research Review, 17, 63-84. http://doi.org/10.1016/j.edurev.2015.11.002

Hoffmann, L. (2002). Promoting girls' interest and achievement in physics classes for beginners. Learning and Instruction, 12(4), 447-465. doi: https://doi.org/10.1016/S09594752(01)00010-X

Hulleman, C.S., Godes, O., Hendricks, B.L., \& Harackiewicz, J.M. (2010). Enhancing interest and performance with a utility value intervention. Journal of Educational Psychology, 102, 880-895. https://doi.org/10.1037/a0019506

Hu, L.T., \& Bentler, P.M. (1999). Cutoff criteria for fit indexes in covariance structure analysis: Conventional criteria versus new alternatives. Structural equation modeling, 6, 1-55. doi:dx.doi.org/10.1080/10705519909540118

James, W. (1983/1892). The principles of psychology. Cambridge, MA: Harvard University Press.

Jansen, M., Lüdtke, O., \& Schroeders, U. (2016). Evidence for a positive relation between interest and achievement: Examining between-person and within-person variation in five domains. Contemporary Educational Psychology, 46, 116-127. doi: https://doi.org/10.1016/j.cedpsych.2016.05.004

Keith, T.Z. (2015). Multiple regression and beyond: An introduction to multiple regression and structural equation modelling (2nd ed.). NY: Routledge.

Knogler, M., Harackiewicz, J.M., Gegenfurtner, A., \& Lewalter, D. (2015). How situational is situational interest? Investigating the longitudinal structure of situational interest. Contemporary Educational Psychology, 43, 39-50. doi: https://doi.org/10.1016/j.cedpsych.2015.08.004

Krapp, A. (2002). Structural and dynamic aspects of interest development: Theoretical considerations from an ontogenetic perspective. Learning and instruction, 12, 383-409. doi: http://doi.org/10.1016/S0959-4752(01)00011-1

Kosovich, J.J., Hulleman, C.S., \& Barron, K.E. (2017). Measuring motivation in educational settings: A Case for pragmatic measurement. To appear in K.A. Renninger and S.E. Hidi (Eds.), The Cambridge Handbook on Motivation and Learning (pp. 39-60). New York, NY: Routledge.

Krapp, A., Hidi, S., \& Renninger, K.A. (1992). Interest, learning, and devel- opment. In K. A. Renninger, S. Hidi, \& A. Krapp (Eds.), The role of inter- est in learning and development (pp. 3-25). Hillsdale, NJ: Lawrence Erlbaum Associates, Inc

Maas, C.J.M. \& Hox, J.L. (2005). Sufficent sample sizes for multilevel modeling. Methodology, 1, 86-92. http://10.1027/1614-2241.1.3.86

Marsh, H. W., Balla, J. R., \& McDonald, R. P. (1988). Goodness-of-fit indexes in confirmatory factor analysis: The effect of sample size. Psychological Bulletin, 103, 391.

Marsh, H.W., Trautwein, U., Lüdtke, Koller, O., Baumert, J. (2005). Academic self-concept, interest, grades, and standardized test scores: Reciprocal effects models of causal ordering. 76, 397-416. http://doi.org/10.1111/j.1467-8624.2005.00853.x 
Marsh, H.W., Nagengast, B., \& Morin, A.J.S. (2013). Measurement invariance of big-five factors over the life span: ESEM tests of gender, age, plasticity, maturity, and la dolce vita effects. Developmental Psychology, 49(6), 1194. http://doi.org/10.1037/a0026913

Moeller, J.,Viljaranta, J., Kracke, B. \& Dietrich, J. (2020). Disentangling objective characteristics of learning situations from subjective perceptions thereof, using an experience sampling method design. Frontline Learning Research, 8(3), 63-84. https://doi.org/10.14786/flr.v8i3.529

Muthén, L., \& Muthén, B. (2014). Mplus Version 7.2. Los Angeles, CA: Mplus

Nuutila, K., Tuominen, H., Tapola, A., Vainikainen, M.-P., \& Niemivirta, M. (2018). Consistency, longitudinal stability, and predictions of elementary school students' task interest, success expectancy, and performance in mathematics. Learning and Instruction, 56, 73-83. http://doi.org/10.1016/j.learninstruc.2018.04.003

Nuutila, K., Tapola, A., Tuominen, H., Kupiainen, S., Pásztor, A., \& Niemivirta, M. (2020). Reciprocal Predictions Between Interest, Self-Efficacy, and Performance During a Task. Frontiers in Education, 5(36). doi:10.3389/feduc.2020.00036

Peterson, E.G., Hidi, S. (2019). Curiosity and interest: current perspectives. Educational Psychology Review. 31, 781-788. https://doi.org/10.1007/s10648-019-09513-0

Raykov, T. (2009). Evaluation of scale reliability for unidimensional measures using latent variable modeling. Measurement and Evaluation in counceling and devlelopment, 42, 223-232. http://doi.org/10.1177/0748175609344096

Renninger, K., Hidi, S., \& Krapp, A. (1992). The role of interest in learning and development. New York: Psychology Press.

Renninger, K.A., \& Su, S. (2019). Interest and Its Development, Revisited. The Oxford Handbook of Human Motivation, Ed R. Ryan. 205-225. Oxford press: NY.

Renninger, K.A. (1992). Individual interest and development: Implications for theory and practice. In K.A. Renninger, S. Hidi, \& A. Krapp (Eds.), The role of interest in learning and development. Hillsdale, NJ: Erlbaum, 361-398.

Renninger, K.A., \& Hidi, S. (2011). Revisiting the conceptualization, measurement, and generation of interest. Educational Psychologist, 46, 168-184. http://doi.org/10.1080/00461520.2011.587723

Renninger, K.A., \& Hidi, S. (2016). The power of interest for motivation and engagement: Routledge.

Renninger, K A., \& Hidi, S.E. (2019). Interest development as a dynamic process in the Workplace. in Vocational Interests in the Workplace: Rethinking Behavior at Work, Christopher D. Nye \& James Rounds eds. pp.39-56. Routledge: NY

Renninger, K.A., Nieswandt, M., \& Hidi, S. (2019). Interest in mathematics and science learning. New York, NY: AERA.

Renninger, K.A., \& Hidi, S.E. (2020). To level the playing field, develop interest. Policy Insights From the Behavioral and Brain Sciences, 7, 10-18. http://doi.org/10.1177/2372732219864705

Renninger, K.A. \& Schofield, L.S. (2014, April). Assessing STEM Interest as a Developmental Motivational Variable. Poster presented as part of a structured poster session (K.A. Renninger \& S. Hidi, Chairs), Current approaches to interest measurement. American Educational Research Association, Philadelphia, PA.

Richardson, M., Abraham, C., \& Bond, R. (2012). Psychological correlates of university students' academic performance: A systematic review and meta-analysis. Psychological Bulletin, 138, 353-387. https://doi.org/10.1037/a0026838.

Rotgans, J.I., \& Schmidt, H.G. (2017). The relation between individual interest and knowledge acquisition. British Educational Research Journal, 43, 350-371. http://doi.org/10.1002/berj.3268 
Rotgans, J.I., \& Schmidt, H.G. (2018). How individual interest influences situational interest and how both are related to knowledge acquisition: A microanalytical investigation. The Journal of Educational Research, 111(5), 530-540. http://doi.org/10.1080/00220671.2017.1310710

Schiefele, U. (1991). Interest, learning, and motivation. Educational Psychologist, 26, 299-333. https://doi.org/10.1080/00461520.1991.9653136.

Schiefele, U. (1992). Topic interest and levels of text comprehension. In A. Renninger, S. Hidi. A. Krapp. The role of interest in learning and development. (pp. 151-183). NY: Taylor Francis.

Schiefele, U. (1996). Topic interest, text representation, and quality of experience. Contemporary Educational Psychology. 21. 3-18 https://doi.org/10.1006/ceps.1996.0002

Schiefele, U., Krapp, A., \& Schreyer, I. (1993). Metaanalysis of the connection between interest and scholastic achievement. Zeitschrift Fur Entwicklungspsychologie Und Padagogische Psychologie, 25(2), 120-148.

Schneider, M., \& Preckel, F. (2017). Variables associated with achievement in higher education: A systematic review of meta-analyses. Psychological Bulletin, 143,

Schwan, S., Grajal, A., \& Lewalter, D. (2014). Understanding and Engagement in Places of Science Experience: Science Museums, Science Centers, Zoos, and Aquariums. Educational Psychologist, 49(2), 70-85 http://doi.org/10.1080/00461520.2014.917588

Shin, D.-J. D., Lee, M., Ha, J.E., Park, J.H., Ahn, H.S., Son, E., et al. (2019). Science for All: Boosting the science motivation of elementary school students with utility value intervention. Learning and Instruction, 60, 104-116. http://doi.org/10.1016/j.learninstruc.2018.12.003

Shum, A., Lau, P. \& Fryer, L. K. (2020) From learner to teacher: (re)training graduate teaching assistants' teaching approaches and developing self-efficacy for and interest in teaching, Higher Education Research \& development, http://doi.org/10.1080/07294360.2020.1818063

Skinner, E.A. (1995). Perceived control, motivation, \& coping (Vol. 8). Sage.

Skinner, E.A. (1996). A guide to constructs of control. Journal of Personality and Social Psychology, 71, 549-570. http://doi.org/10.1037/0022-3514.71.3.549

Skinner, E.A., Zimmer-Gembeck, M.J., Connell, J.P., \& Wellborn, J.G. (1998). Individual Differences and the Development of Perceived Control. Monographs of the Society for Research in Child Development, 63.

Thoman, D.B., Sansone, C., \& Geerling, D. (2017). The dynamic nature of interest: Embedding interest within self- regulation. In P.A. O'Keefe \& J.M. Harackiewicz (Eds.), The science of interest (pp. 27-47). Cham, Switzerland: Springer.

Tobias, S. (1994). Interest, Prior Knowledge, and Learning. Review of Educational Research, 64(1), 37-54. https://doi.org/10.3102/00346543064001037

Tschannen-Moran, M., \& Hoy, A. W. (2001). Teacher efficacy: capturing an elusive construct. Teaching and Teacher Education, 17, 783-805. https://doi.org/10.1016/S0742051X(01)00036-1

Walkington, C., \& Bernacki, M.L. (2019). Personalizing algebra to students' individual interests in an intelligent tutoring system: moderators of impact. International Journal of Artificial Intelligence in Education, 29, 58-88. http://doi.org/10.1007/s40593-018-0168-1

Xu, J., Coats, L.T., \& Davidson, M.L. (2012). Promoting student interest in science. American Educational Research Journal, 49, 124-154. http://doi.org/10.3102/0002831211426200

$\mathrm{Xu}$, J. (2018). Reciprocal effects of homework self-concept, interest, effort, and math 
achievement. Contemporary Educational Psychology, 55, 42-52.

http://doi.org/10.1016/j.cedpsych.2018.09.002 


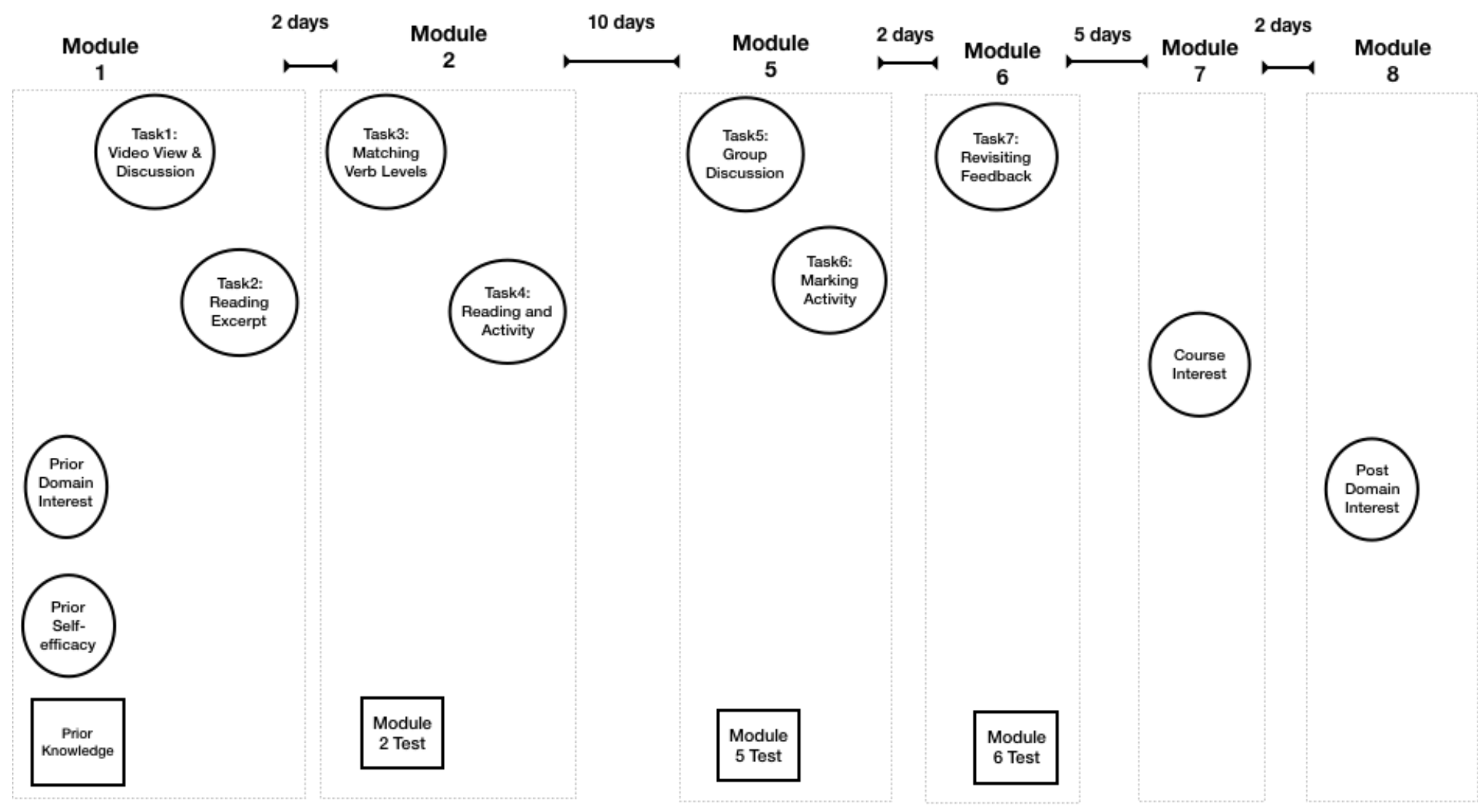

Figure 1. Research design

Note: SEM analysis of these variables was fully forward, meaning that all prior variables were modelled as predicting all future variables. Note: Sequence of measurements are presented left to right. Each module was 3 hours long. 


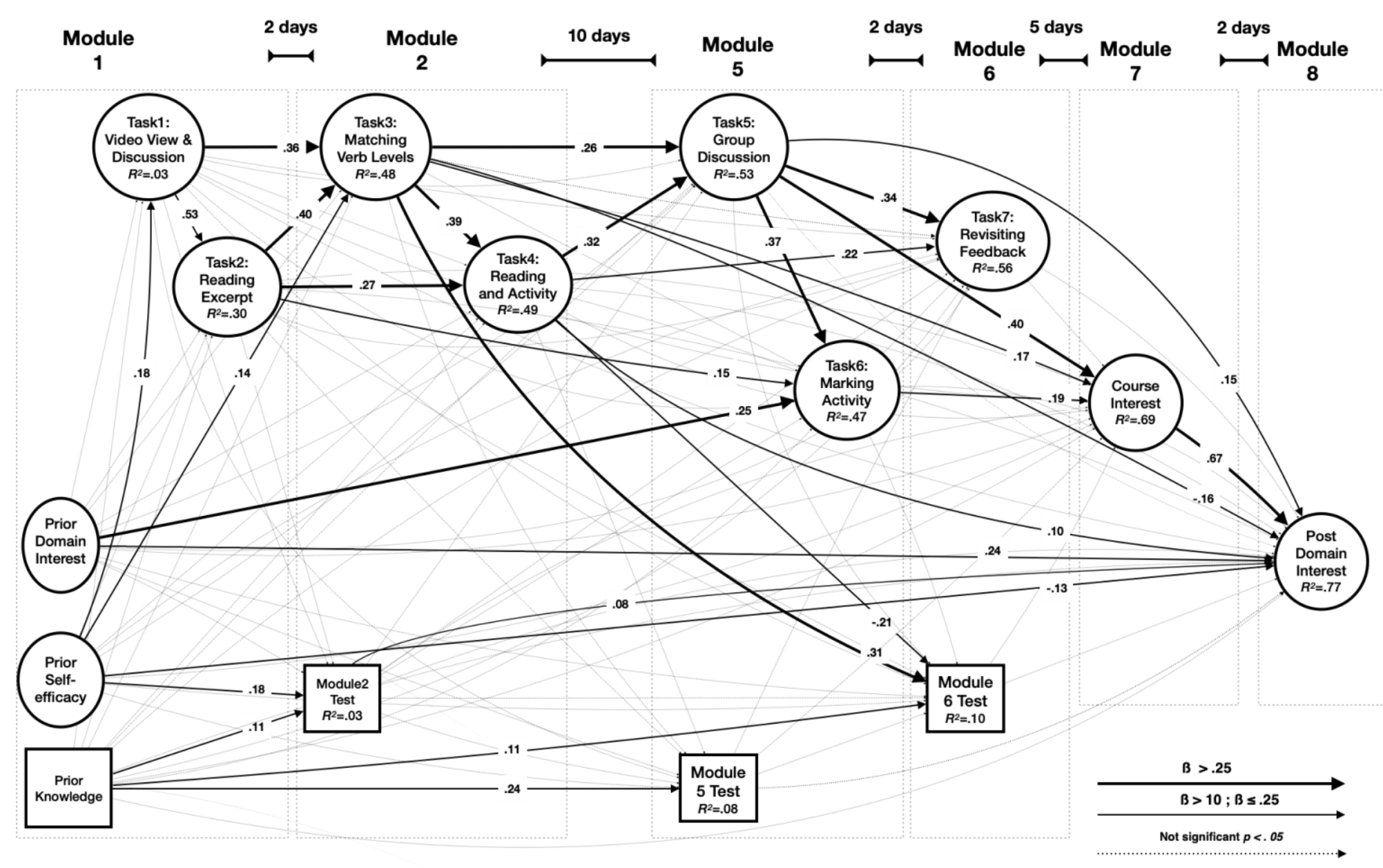

Figure 2. Fully-forward (test of all $\beta$ s for all future variables) model test

Note: Sequence of measurements left to right. Modules were 3 hours long each. Task1 refers to Task interest for Task 1 . Same for all Tasks presented in the figure. The fainter gray arrows represent $\beta$ s not reaching significance $(.05<p)$, values are included in the appendices Table 4 . 
Table 2. Correlations, Raykov’s Rho, Means and SD

\begin{tabular}{|c|c|c|c|c|c|c|c|c|c|c|c|c|c|c|c|}
\hline & $\begin{array}{l}\text { Prior } \\
\text { Domain } \\
\text { Interest }\end{array}$ & Prior Self-efficacy & $\begin{array}{l}\text { Prior } \\
\text { Knowledge }\end{array}$ & $\begin{array}{l}\text { Module } \\
2 \text { Test } 1\end{array}$ & $\begin{array}{l}\text { Task } \\
\text { Interest } \\
1 \\
\end{array}$ & $\begin{array}{l}\text { Task } \\
\text { Interest } 2\end{array}$ & $\begin{array}{l}\text { Task } \\
\text { Interest } 3\end{array}$ & $\begin{array}{l}\text { Task } \\
\text { Interest } 4\end{array}$ & $\begin{array}{l}\text { Task } \\
\text { Interest } 5\end{array}$ & $\begin{array}{l}\text { Task } \\
\text { Interest } 6\end{array}$ & $\begin{array}{l}\text { Module } \\
5 \text { Test } 2\end{array}$ & $\begin{array}{l}\text { Task } \\
\text { Interest } 7\end{array}$ & $\begin{array}{l}\text { Module } \\
6 \text { Test } 3\end{array}$ & $\begin{array}{l}\text { Course } \\
\text { Interest }\end{array}$ & $\begin{array}{l}\text { Post } \\
\text { Domain } \\
\text { Interest }\end{array}$ \\
\hline \multicolumn{16}{|l|}{ Prior Domain Interest } \\
\hline Prior Self-efficacy & $.67 * *$ & & & & & & & & & & & & & & \\
\hline Prior Knowledge & .09 & .04 & & & & & & & & & & & & & \\
\hline Module 2 Test 1 & .03 & $.15^{*}$ & .15 & & & & & & & & & & & & \\
\hline Task Interest 1 & .09 & $.16^{*}$ & .01 & .07 & & & & & & & & & & & \\
\hline Task Interest 2 & .08 & $.16^{* *}$ & -.06 & .07 & $.54 * *$ & & & & & & & & & & \\
\hline Task Interest 3 & .09 & $.21 * *$ & -.02 & .02 & $.59 * *$ & $.61^{* * *}$ & & & & & & & & & \\
\hline Task Interest 4 & $.15^{*}$ & $.16^{* *}$ & -.09 & -.05 & $.52 * *$ & $.58^{* * *}$ & $.64 * *$ & & & & & & & & \\
\hline Task Interest 5 & .10 & $.18^{* * *}$ & -.05 & .01 & $.54 * *$ & $.57^{* *}$ & $.64 * *$ & $.65^{* *}$ & & & & & & & \\
\hline Task Interest 6 & $.20 * *$ & .12 & -.01 & .00 & $.46^{* *}$ & $.51^{* * *}$ & $.54 * *$ & $.52 * *$ & $.62 * *$ & & & & & & \\
\hline Module 5 Test 2 & -.01 & -.09 & .15 & $.37^{* *}$ & -.05 & -.10 & -.09 & -.06 & .06 & -.10 & & & & & \\
\hline Task Interest 7 & .14 & $.17 * *$ & -.09 & -.08 & $.41 * *$ & $.54 * *$ & $.60 * *$ & $.63^{* *}$ & $.67^{* *}$ & $.53 * *$ & -.03 & & & & \\
\hline Module 6 Test 3 & .08 & .09 & .15 & $.21 * *$ & .00 & .06 & .16 & -.04 & .07 & .03 & $.19^{*}$ & .03 & & & \\
\hline Course Interest & .12 & $.20^{* *}$ & -.06 & .06 & $.50^{* *}$ & $.53 * *$ & $.66^{* *}$ & $.62 * *$ & $.77^{* *}$ & $.63 * *$ & -.03 & $.66^{* *}$ & .11 & & \\
\hline Post Domain Interest & $.26 * *$ & $.22 * *$ & -.07 & .13 & $.45^{* *}$ & $.54 * *$ & $.54 * *$ & $.60^{* *}$ & $.71^{* *}$ & $.58 * *$ & -.01 & $.62 * *$ & $.15^{*}$ & $.83 * *$ & \\
\hline Raykov's Rho & .94 & .92 & & & .92 & .94 & .93 & .96 & .97 & .96 & & .97 & & .92 & .92 \\
\hline Mean & 1.56 & 1.97 & 3.33 & 2.78 & 3.72 & 3.20 & 3.51 & 3.26 & 2.61 & 3.61 & 3.51 & 2.89 & 3.65 & 3.32 & 3.45 \\
\hline SD & .79 & .89 & 1.21 & 1.18 & .89 & .98 & 1.11 & 1.13 & 1.17 & 1.06 & 1.08 & 1.03 & 1.04 & 1.22 & .93 \\
\hline
\end{tabular}

note: $*=p<.05 ; * *=p<.01$ 
Table 3. Fit for Configural, Invariance and Final Model

\begin{tabular}{lllll}
\hline & Configural CFA & $\begin{array}{l}\text { Domain Interest- } \\
\text { Invariance test }\end{array}$ & $\begin{array}{l}\text { Task Interest-invariance } \\
\text { test }\end{array}$ & Final Model \\
\hline CFI & .97 & .97 & .97 & .97 \\
TLI & .96 & .96 & .96 & .96 \\
SRMR & .033 & .034 & .034 & .034 \\
RMSEA & .038 (C.I. .032-.044) & .038 (C.I. .032-.044) & .038 (C.I. .032-.043) & .038 (C.I. .032-.044) \\
$X^{2}$ & $805.57(564)$ & $816.83(566)$ & $820.118(576)$ & $9113.26(703)$ \\
\hline
\end{tabular}




\section{Appendices}

Table 1 Description of tasks assessed for interest during the study

\begin{tabular}{|c|c|}
\hline$\underline{\text { Tasks }}$ & $\begin{array}{l}\text { Expectations regarding students' cognitive } \\
\text { operations during tasks }\end{array}$ \\
\hline \multicolumn{2}{|l|}{ Module 1 - Task 1 - Video viewing and group discussion } \\
\hline $\begin{array}{l}\text { Students formed four groups. Each group was assigned with different focuses of classroom teaching skills, such as communication, } \\
\text { student engagement, etc. While watching a short video clip, students were required to observe the teaching skills individually and to } \\
\text { take notes regarding the assigned focus. They then compared the notes in the group and discussed good practices or areas for } \\
\text { improvement. Finally, each group summarised their views and shared to the whole class in order to co-construct a whole picture of good } \\
\text { classroom teaching. }\end{array}$ & $\begin{array}{l}\text { - Generation of ideas } \\
\text { - Comparison of different views } \\
\text { - Construction of knowledge with peers }\end{array}$ \\
\hline \multicolumn{2}{|l|}{ Module 1 - Task 2 - Reading of excerpt: connections between teaching and research } \\
\hline $\begin{array}{l}\text { This post-module task was designed to encourage participants to reflect on the topics in Module } 1 \text {. After reading an excerpt from a } \\
\text { published book, students reflected on the connections between teaching and research by answering two reflective questions provided. }\end{array}$ & - Reflection of presented texts \\
\hline \multicolumn{2}{|l|}{ Module 2 - Task 3 - Fill in a structure handout organising verbs into appropriate learning levels } \\
\hline $\begin{array}{l}\text { Students were tasked to match various action verbs with appropriate levels in worksheet provided, based on their own understanding. } \\
\text { Instructor shared the answers and provided further explanations to clarify any misconceptions. }\end{array}$ & $\begin{array}{l}\text { - Interpretation of presented materials } \\
\text { - Classification }\end{array}$ \\
\hline \multicolumn{2}{|l|}{ Module 2 - Task 4 - Reading and highlighting activity } \\
\hline $\begin{array}{l}\text { Two short readings about students' motivation to learn and teachers' drive to teach in mandatory courses were provided to students. } \\
\text { Based on the readings, they were tasked to identify any tips that might be useful in dealing with apathetic students. Finally, students } \\
\text { were required to share with neighbours how they plan to use those tips in their initial teaching practice. }\end{array}$ & $\begin{array}{l}\text { - Conceptualisation } \\
\text { - Formation of lesson plan }\end{array}$ \\
\hline \multicolumn{2}{|l|}{ Module 5 - Task 5 - Group discussion } \\
\hline $\begin{array}{l}\text { Students were grouped to discuss two cases relating different assessment designs and student's perceptions about course assessments. } \\
\text { They summarised the strengths and limitations of assessment designs, and various implications on student learning. }\end{array}$ & $\begin{array}{l}\text { - Case analyses } \\
\text { - Comparison of assessment design }\end{array}$ \\
\hline \multicolumn{2}{|l|}{ Module 5 - Task 6 - Marking activity } \\
\hline $\begin{array}{l}\text { This activity provided students with hands-on experience to mark authentic student works (such as a short essay in an education course), } \\
\text { and to go through a peer moderation process. Students were required to mark individually and to give feedback to the student works. } \\
\text { Then, they compared their initial results and feedback in groups to reach a consensus. Finally, instructor explained the results and } \\
\text { feedback made by the course teachers. }\end{array}$ & $\begin{array}{l}\text { - Interpretation of assessment criteria } \\
\text { - Evaluation of student sample works } \\
\text { - Team decision-making }\end{array}$ \\
\hline \multicolumn{2}{|l|}{ Module 6 - Task 7 - Revisiting Feedback } \\
\hline $\begin{array}{l}\text { Students were paired. They retrieved one feedback that they had written for each other on their initial teaching practices in last week. } \\
\text { They were required to rewrite the feedback after reading a short article on principles of good feedback and listening to the peer about } \\
\text { his/her feelings on the initial feedback. Their peers received the new feedback at the end. }\end{array}$ & $\begin{array}{l}\text { - Self-evaluation } \\
\text { - Revision of feedback }\end{array}$ \\
\hline
\end{tabular}


Table 4 Full regression results for structural equation model

\begin{tabular}{|c|c|c|c|c|c|c|c|c|c|c|c|c|c|c|c|c|c|c|c|c|c|c|c|c|}
\hline & \multicolumn{2}{|c|}{$\begin{array}{l}\text { Post Domain } \\
\text { Interest }\end{array}$} & \multicolumn{2}{|c|}{ Course Interest } & \multicolumn{2}{|c|}{ Task Interest 7} & \multicolumn{2}{|c|}{ Task Interest 6} & \multicolumn{2}{|c|}{ Task Interest 5} & \multicolumn{2}{|c|}{ Task Interest 4} & \multicolumn{2}{|c|}{ Task Interest 3} & \multicolumn{2}{|c|}{ Task Interest 2} & \multirow{2}{*}{$\begin{array}{c}\text { Task Interest } 1 \\
\beta\end{array}$} & \multicolumn{3}{|c|}{$\begin{array}{l}\text { Module } 6 \\
\text { Test } 3\end{array}$} & \multicolumn{2}{|c|}{$\begin{array}{c}\text { Module } 5 \\
\text { Test } 2\end{array}$} & \multicolumn{2}{|c|}{$\begin{array}{c}\text { Module } 2 \\
\text { Test } 1\end{array}$} \\
\hline & $\beta$ & $p$ & $\beta$ & $p$ & $\beta$ & $p$ & $\beta$ & $p$ & $\beta$ & $p$ & $\beta$ & $p$ & $\beta$ & $p$ & $\beta$ & $p$ & & $p$ & $\beta$ & $p$ & $\beta$ & $p$ & $\beta$ & $p$ \\
\hline Task Interest 1 & .01 & .94 & .01 & .87 & -.10 & .12 & .07 & .44 & .14 & .06 & .14 & .19 & $.36^{* *}$ & .00 & $.53^{* *}$ & .00 & & & -.11 & .21 & .01 & .93 & .02 & .77 \\
\hline Task Interest 2 & .12 & .06 & -.03 & .65 & .12 & .15 & $.15^{*}$ & .04 & .14 & .10 & $.27^{* *}$ & .01 & $.40^{* *}$ & .00 & & & & & .04 & .53 & -.06 & .69 & .03 & .71 \\
\hline Task Interest 3 & $-.16^{* *}$ & .00 & $.17^{*}$ & .04 & .17 & .06 & .16 & .16 & $.26^{* *}$ & .00 & $.39 * *$ & .00 & & & & & & & $.31^{* *}$ & .01 & -.05 & .65 & & \\
\hline Task Interest4 & $.10^{*}$ & .04 & .07 & .27 & $.22^{* *}$ & .00 & .05 & .66 & $.32^{* *}$ & .00 & & & & & & & & & $-.21 *$ & .03 & .06 & .58 & & \\
\hline Task Interest 5 & 13 & .11 & $.39 * *$ & .00 & $.34^{* *}$ & .00 & $.37 * *$ & .00 & & & & & & & & & & & .05 & .68 & & & & \\
\hline Task Interest 6 & -.03 & .64 & $.19 *$ & .02 & .10 & .25 & & & & & & & & & & & & & -.05 & .52 & & & & \\
\hline Task Interest 7 & .07 & .30 & .17 & .09 & & & & & & & & & & & & & & & & & & & & \\
\hline Course Interest & $.67 * *$ & .00 & & & & & & & & & & & & & & & & & & & & & & \\
\hline Prior Domain Interest & $24 * *$ & .00 & -.05 & .39 & .02 & .85 & $.25 * *$ & .00 & -.01 & .81 & .13 & .11 & -.07 & .36 & -.02 & .81 & -.03 & .77 & .08 & .39 & .04 & 11 & -.10 & .26 \\
\hline Prior Self-efficacy & $-.13^{* *}$ & .01 & .06 & .32 & .03 & .78 & -.19 & .09 & .04 & .34 & -.07 & .35 & $.14^{*}$ & .01 & .09 & .32 & $.18^{*}$ & .04 & -.01 & .96 & -.10 & .71 & $.18^{*}$ & .03 \\
\hline Module 2 Test 1 & $.08^{*}$ & .01 & .05 & .16 & -.06 & .15 & .00 & .96 & .00 & .97 & -.06 & .17 & -.05 & .22 & & & & & .07 & .21 & .10 & 22 & & \\
\hline Module 5 Test 2 & -.02 & .62 & -.01 & .79 & .01 & .92 & & & & & & & & & & & & & .11 & .05 & & & & \\
\hline Module 6 Test 3 & .07 & .06 & .04 & .32 & & & & & & & & & & & & & & & & & & & & \\
\hline Prior knowledge & -.04 & .32 & -.02 & .53 & .02 & .85 & .00 & .93 & -.01 & .88 & -.06 & .26 & .01 & .74 & -.06 & .38 & .01 & .78 & $.11^{*}$ & .02 & $.24 * *$ & .00 & $.11 *$ & .04 \\
\hline
\end{tabular}

note: ${ }^{*} p<.05 ; * * p<.01$ 


\section{Supplemental Materials}

\section{Table 5 Formative Tests for Module 1 (prior knowledge), Module 2, Module 5 and Module 6}

\section{Prior knowledge Module 1}

What does SOLO stand for in teaching and learning?

Solar and Heliospheric Observatory

Student Organisations and Leadership Opportunities

Structure of the Observed Learning Outcome (correct answer)

Sounding Oceanographic Lagrangian Observer

Which of the following indicate descending order of levels of understanding in SOLO taxonomy?

Prestructural, Multistructural, Unistructural, Relational, Extended abstract.

Multistructural, Unistructural, Relational, Extended abstract, Prestructural.

Prestructural, Extended abstract, Multistructural, Unistructural, Relational.

Extended abstract, Relational, Multistructural, Unistructural, Prestructural. (correct answer)

With regard to the vision and mission of HKU 2016-2015, which aspect of the strategic plan targets the wish to continue encouraging critical questioning and thinking to innovate for change and social good?

Internationalisation

Impact

Innovation (correct answer)

Interdisciplinarity

Which of the following is an incorrect statement about constructive alignment?

Learning outcomes have to be gradually revealed to the students through learning activities and assessment. (correct answer)

Learning activities should be organised so that students will likely to achieve those outcomes.

Learning outcomes state what is to be achieved in fulfilment of the aims.

Assessment must be designed such that students are able to demonstrate that they have met the learning outcomes.

Teachers can motivate students by:

communicating clearly

creating situations that allow student to make and correct mistakes

showing teachers, enthusiasm for the subject matter

all of the above (correct answer)

Which of the following strategies does NOT help students to overcome a passive approach to the subject?

Frequent formation of discussion groups in class.

Frequent high-stakes testing (test with important consequences for the test taker) during the course. (correct answer)

Problem-based learning (PBL) project based on real-life examples.

Providing hands-on practice outside class time. 


\section{Module 2 Test}

$1 \quad$ What does SOLO stands for in teaching and learning?

Solar and Heliospheric Observatory

Student Organizations and Leadership Opportunities

Structure of the Observed Learning Outcome (correct answer)

Sounding Oceanographic Lagrangian Observer

Which of the following indicate descending order of levels of understanding in SOLO taxonomy?

Prestructural, Multistructural, Unistructural, Relational, Extended abstract.

Multistructural, Unistructural, Relational, Extended abstract, Prestructural.

Prestructural, Extended abstract, Multistructural, Unistructural, Relational.

Extended abstract, Relational, Multistructural, Unistructural, Prestructural. (correct answer)

With regard to the vision and mission of HKU 2016-2015, which aspect of the , targets the wish to continue encouraging critical questioning and thinking to innovate for change and social good?

Internationalisation

Impact

Innovation (correct answer)

Interdisciplinarity

Which of the following is an incorrect statement about constructive alignment?

Learning outcomes have to be gradually revealed to the students through learning activities and assessment. (correct answer)

Learning activities should be organized so that students will likely to achieve those outcomes.

Learning outcomes state what is to be achieved in fulfilment of the aims.

Assessment must be designed such that students are able to demonstrate that they have met the learning outcomes.

Teachers can motivate students by:

communicating clearly

creating situations that allow student to make and correct mistakes

showing teachers, enthusiasm for the subject matter

all of the above (correct answer)

Which of the following strategies does NOT help students to overcome a passive approach to the subject?

Frequent formation of discussion groups in class.

Frequent high-stakes testing (test with important consequences for the test taker) during the course. (correct answer)

Problem-based learning (PBL) project based on real-life examples.

Providing hands-on practice outside class time. 


\section{Module 5 Test}

Which of the following is NOT mentioned in the Assessment Policy of HKU?

Teachers must provide individual feedback to student performance within two weeks of the submission deadline. (correct answer)

Expected standards of performance at different levels should be made explicit in the descriptive statements which correspond to each grade awarded.

Students are expected to be able to give feedback to their teachers/faculty on their perception of assessment tasks.

Assessment needs to be both summative and formative.

Internationally, there is a shift from -referenced assessment to -referenced assessment or -referenced assessment

standard, norm, ipsative

confirmative, ipsative, criterion

summative, formative, ipsative

norm, criterion, standard (correct answer)

Which of the following description about grade descriptor is NOT true?

Specific grade descriptors should be included in the course outline of each course.

Grade descriptors promote consistency in standards when there are multiple markers. It is particularly important if new teaching staff is involved.

Grade descriptors enable students to understand the level of performance expected and the nature of the exemplary work.

At the beginning of each course, model answers or exemplars should be provided to students such that they could imitate them. (correct answer)

Which of the following description about moderation of grading is true?

Before actual marking, moderation of grading should be done when there are two or more teachers for the same course. (correct answer)

Moderation of grading aims to ensure a common understanding of the grade descriptors, but not the grading standards, among teachers.

Moderation of grading means assigning the same number of A, B, Cs to students from one tutorial group to another within the same course.

Moderation of grading involves grading of all student assignments/scripts.

\section{Reliability}

Validity (correct answer)

Measurability

Familiarity

Which of the following is NOT a key feature of assessment criteria?

Undisclosed until students submitted their assessment tasks (correct answer)

Achievable through the assessment task

Appropriate for learning outcome and context

Used as a basis of feedback to students 


\section{Module 6 Test}

1 To ensure validity of assessment, which of the following strategies is necessary?

Providing clear description of the assessment

Grading by multiple markers

Using assessment criteria

Aligning assessment with learning outcomes (correct answer)

Which of the following elements is NOT included in assessment criteria description?

Level of performance

Aims of assessment

Expected standards

Examples of student works (correct answer)

Which of the following description about good feedback is NOT correct?

Good feedback should be given to students timely.

Good feedback should only provide praise. (correct answer)

Good feedback should be constructive and tell students where their weaknesses lie.

Good feedback should include possible action plan(s) for improvement so that students know what to do next.

The three levels of feedback includes an

self feedback, peer feedback, teacher feedback

task feedback, peer feedback, outcome feedback

task feedback, process feedback, self-regulation feedback (correct answer)

task feedback, process feedback, self-assessment feedback

To ensure students receive and understand teachers' feedback, teachers could encourage students to:

summarise the comments with the former students of the same course.

reply to the feedback, such as to clarify necessary actions to improve. (correct answer)

interpret the feedback on their own.

compare their own works with the exemplars.

Which of the following strategies is NOT part of assessment of learning?

Selecting the evidence

Setting the criteria

Support students with feedback (correct answer)

Making a judgment 
Table 6 Scales for the present study

\section{Prior Domain Interest}

1 How much do you know about teaching?

2 In your spare time, how often have you tried to learn about teaching?

3 I have spent time learning about teaching on my own. How well does this statement match you?

\section{Post Domain Interest}

1 How much do you know about teaching?

2 In your future spare time, how much will you try to learn about teaching?

3 I will spend time learning about teaching on my own. How well does this statement match you?

\section{Activity/Task Interest}

1 This activity/task is personally meaningful.

2 This activity/task is interesting.

3 I want to learn by doing activities/tasks like this.

\section{Course Interest}

1 This course is personally meaningful.

2 This course is interesting.

3 I want more courses like this.

\section{Teachers sense of self-efficacy (Prior Self-efficacy)}

1 I can craft good questions for students.

2 I can help students value their learning.

3 I can foster students' creativity.

4 I can help students think critically. 